\title{
The different effects of gonadotropin-releasing hormone agonist therapy on body mass index and growth between normal-weight and overweight girls with central precocious puberty
}

\author{
Won Jun Yang, MD', \\ Keun Hyeok Ko, MD', \\ Kon Hee Lee, MD, PhD', \\ II Tae Hwang, MD, PhD', \\ Yeon Joung $\mathrm{Oh}, \mathrm{MD}^{1}$
}

${ }^{1}$ Department of Pediatrics, Hallym University Kangnam Sacred Heart Hospital, Hallym University College of Medicine, Seoul, ${ }^{2}$ Department of Pediatrics, Hallym University Kangdong Sacred Heart Hospital, Hallym University College of Medicine, Seoul, Korea

\begin{abstract}
Purpose: The effects of gonadotropin-releasing hormone agonist (GnRHa) treatment on body mass index (BMI) are controversial in girls with central precocious puberty (CPP). We therefore evaluated auxological parameters during GnRHa therapy in patients with CPP, specifically focusing on changes in BMI.

Methods: Seventy-seven girls with idiopathic CPP who underwent GnRHa therapy were retrospectively recruited. We investigated $\mathrm{BMI}$ changes during the treatment period after stratifying them according to baseline BMI status as follows: normal (BMI percentile of $<85$ th) and overweight groups (BMI percentile of $\geq 85$ th).

Results: The incidence of overweight/obesity (40.3\%/23.4\%) was very high in the girls with CPP. In the overall study population, no significant BMI change was observed during the GnRHa treatment period. However, when stratified according to baseline BMI status, the normal-weight group showed a significant increase in BMI-standard deviation score (SDS), whereas the overweight group showed no change in BMI-SDS. Baseline BMI-SDS was an independent predictor of changes in BMI during the GnRHa treatment period. Changes in weight-SDS were similar, but changes in height-SDS were significantly greater in the overweight group than in the normal-weight group, which explains the observed difference in BMI-SDS.

Conclusion: Our results demonstrate that the difference in the pattern of BMI changes among our CPP patients suggests that delayed puberty induced by $\mathrm{GnRHa}$ treatment may have different effects on linear growth according to baseline body composition. This study underscores the importance of individualized lifestyle intervention in CPP children.
\end{abstract}

Keywords: Gonadotropin-releasing hormone agonist, Body mass index, Overweight, Obesity, Central precocious puberty

\section{Introduction}

Central precocious puberty (CPP) in girls is defined as the development of sexual characteristics before the age of 8 years that result from premature activation of the hypothalamic-pituitary-gonadal axis ${ }^{1}$. For over 30 years, gonadotropin-releasing hormone agonist (GnRHa) has been used in the treatment of $\mathrm{CPP}^{2)}$. Nonpulsatile administration of GnRHa effectively desensitizes the pituitary response to GnRH by downregulating the GnRH receptors, thereby suppressing the acceleration of bone maturation and premature pubertal development ${ }^{3)}$. The benefits of GnRHa therapy include arrest or regression of secondary sexual characteristics, delayed menarche, and maximization of linear growth ${ }^{4,5)}$.

Childhood obesity has become a major health concern in recent decades since it was known 
as an independent predictor of short- and long-term metabolic and cardiovascular morbidities ${ }^{6}$. In addition, excess adiposity during childhood is closely associated with growth and early pubertal development ${ }^{7}$. Although the prevalence of obesity was reported to be higher in children with CPP than in the general population ${ }^{8,9}$, previous studies that evaluated the effect of GnRHa therapy on auxological parameters in CPP patients mainly focused on the improvement of final height ${ }^{10,11)}$, and less attention has been paid to its impact on body composition ${ }^{1)}$. In fact, limited, even somewhat controversial, data are available regarding the effects of GnRHa treatment on body mass index (BMI). Some studies demonstrated a significant increase in BMI during and after GnRHa treatment ${ }^{12-15}$, whereas others reported a lack of relationship between GnRHa administration and changes in body composition ${ }^{13,16-18}$, or even a reduction in $\mathrm{BMI}^{19,20)}$. Despite the general agreement that GnRHa treatment does not pose an additional risk of developing obesity, a recent report suggested that baseline weight status might influence BMI parameters after treatment ${ }^{21)}$.

In the present study, we retrospectively evaluated girls with CPP with different BMIs to (1) determine the factors that affect changes in body composition and (2) investigate whether serially assessed BMI differed between overweight and normalweight patients during GnRHa treatment.

\section{Materials and methods}

\section{Subjects}

The hospital records of 77 girls diagnosed with idiopathic CPP at Hallym University Kangnam Sacred Heart Hospital were retrospectively reviewed. All the subjects received GnRHa, and the treatment was completed prior to the commencement of the study. CPP was diagnosed according to the following criteria: (1) objective breast budding appearing before the age of 8 years; (2) advanced bone age (BA), at least 1 year ahead of chronological age (CA); (3) significantly higher peak luteinizing hormone values than the cutoff value of $5 \mathrm{IU} / \mathrm{L}$, according to the result of a GnRH stimulation test conducted before the age of 9 years; and (4) the absence of pathology on a brain magnetic resonance imaging scan.

\section{Methods}

All the patients were treated with leuprolide acetate at $75-$ $100 \mu \mathrm{g} / \mathrm{kg}$ every 28 days. The patients were encouraged to visit the hospital regularly, and changes in height, weight, and sexual maturity were monitored every 3 months. Height was measured by using the Harpenden stadiometer (Seca, Hamburg, Germany), and body weight was measured by using a digital scale (Dong-Sahn Jenix, Seoul, Korea). BMI was calculated as weight $(\mathrm{kg})$ divided by the square of height $\left(\mathrm{m}^{2}\right)$. We evaluated height, weight, BMI, and BA at the onset of GnRHa treatment, 12 months later, and at the end of the treatment. The subjects were divided into 2 groups, the normal-weight and overweight groups, based on baseline BMI. Patients with BMI percentiles $\geq 85$ th were allocated to the overweight group. Height, weight, and BMI were expressed as a standard deviation score (SDS) according to age- and sex-matched Korean standards 2007. BA was evaluated every 6 months by a single observer based on a X-ray of the left hand, according to the Greulich and Pyle method. Predicted adult height was estimated using the Bayley-Pinneau method ${ }^{22)}$. Sexual maturity rating according to the Tanner staging system was assessed by one pediatric endocrinologist. This study was approved by the Institutional Review Board of Hallym University Medical Center, Seoul, Korea (approval number: 2016-02-07).

\section{Statistical analyses}

Values are expressed as mean \pm standard devaiton or estimated mean \pm standard error. All SDS values are expressed relative to CA. Comparisons of the results were assessed by using

Table 1. Baseline characteristics of the 77 girls with central precocious puberty

\begin{tabular}{|c|c|c|c|c|}
\hline Variable & Total $(n=77)$ & Normal-weight $(n=46)$ & Overweight $(n=31)$ & $P$-value \\
\hline CA (yr) & $8.6 \pm 0.5$ & $8.6 \pm 0.3$ & $8.4 \pm 0.6$ & 0.047 \\
\hline $\mathrm{BA}(\mathrm{yr})$ & $10.3 \pm 0.6$ & $10.3 \pm 0.5$ & $10.4 \pm 0.8$ & 0.841 \\
\hline BA advancement (yr) & $1.8 \pm 0.5$ & $1.7 \pm 0.5$ & $2.0 \pm 0.6$ & 0.020 \\
\hline $\mathrm{MPH}(\mathrm{cm})$ & $165.4 \pm 4.6$ & $165.9 \pm 4.3$ & $164.6 \pm 4.9$ & 0.207 \\
\hline PAH (cm) & $160.3 \pm 5.6$ & $160.3 \pm 5.3$ & $160.3 \pm 6.0$ & 0.988 \\
\hline Treatment duration (mo) & $30.7 \pm 8.4$ & $29.1 \pm 7.3$ & $33.1 \pm 9.4$ & 0.049 \\
\hline Height (cm) & $136.0 \pm 5.6$ & $136.0 \pm 4.8$ & $135.9 \pm 6.8$ & 0.960 \\
\hline Height-SDS & $1.3 \pm 0.8$ & $1.2 \pm 0.7$ & $1.5 \pm 0.9$ & 0.177 \\
\hline Weight (kg) & $35.1 \pm 6.1$ & $31.9 \pm 3.7$ & $39.8 \pm 5.9$ & $<0.001$ \\
\hline Weight-SDS & $1.2 \pm 0.8$ & $0.7 \pm 0.6$ & $1.9 \pm 0.5$ & $<0.001$ \\
\hline $\mathrm{BMI}\left(\mathrm{kg} / \mathrm{m}^{2}\right)$ & $18.9 \pm 2.6$ & $17.2 \pm 1.4$ & $21.4 \pm 1.8$ & $<0.001$ \\
\hline BMI-SDS & $0.8 \pm 1.0$ & $0.2 \pm 0.7$ & $1.7 \pm 0.4$ & $<0.001$ \\
\hline
\end{tabular}

Values are presented as mean \pm standard deviation.

CA, chronological age; BA, bone age; MPH, mid parental height; PAH, predicted adult height; SDS, standard deviation score; BMI, body mass index. 
the Student $t$-test or Mann-Whitney test, according to data distribution. The chi-square test was also used. For longitudinal comparisons, repeated-measures analysis of variance was performed. Analysis of covariance was used to determine the covariate-adjusted differences across the weight groups. Stepwise multiple linear regression analyses were performed to evaluate the factors that affect change in BMI-SDS during the $\mathrm{GnRHa}$ treatment. Statistical analyses were performed by using IBM SPSS Statistics ver. 19.0 (IBM Co., Armonk, NY, USA), and a $P$-value of $<0.05$ was considered statistically significant.

\section{Results}

\section{Baseline characteristics of the patients}

The baseline characteristics of the patients at the onset of GnRHa therapy are shown in Table 1. In our overall study population, the mean CA and BA were $8.6 \pm 0.5$ and $10.3 \pm 0.6$ years, respectively, and the mean treatment duration was $30.7 \pm 8.4$ months. Of the 77 patients, 46 (59.7\%) were in the normal-weight group and $31(40.3 \%)$ were in the overweight group. Among the baseline variables, except for body composition indexes, CA and BA advancement were significantly different between the normal-weight and the overweight groups (age: $8.6 \pm 0.3$ years vs. $8.4 \pm 0.6$ years, $P=0.047$; BA advancement: $1.7 \pm 0.5$ years vs. $2.0 \pm 0.6$ years, $P=0.020$ ). The mean treatment duration was slightly longer in the overweight group than in the normal-weight group (33.1 \pm 9.4 months vs. $29.1 \pm 7.3$ months, $P=0.049$ ).

\section{Prevalence of overweightness and obesity}

At the onset of treatment, 13 of all the patients (16.9\%) were overweight (85th percentile $\leq \mathrm{BMI}<95$ th percentile) and 18 $(23.4 \%)$ were obese (BMI $\geq 95$ th percentile). At 12 months later, the proportion of overweight children increased $(+5.2 \%)$, while the number of children with overt obesity decreased (-1.3\%). At the end of the GnRHa treatment, 15 (19.5\%) were overweight, and another 15 were obese. However, the overall difference in BMI-SDS between before and after treatment was not statistically significant (Table 2).

\section{Changes in BMI-SDS and height-SDS during GnRHa treatment}

In the overall study population, a slight, but not significant, increase in BMI-SDS was noted (from $0.83 \pm 0.95$ at the start of therapy to $0.87 \pm 0.85$ at the end of therapy, $P=0.492$ ). When stratified according to baseline weight status, the normalweight group showed a significant increase in BMI-SDS at 12 months $(0.36 \pm 0.63, P=0.027)$ and at the end of treatment $(0.39 \pm 0.67, P=0.025)$ as compared with the pretreatment BMISDS $(0.24 \pm 0.73)$. On the other hand, the overweight group had a stable BMI-SDS during the treatment period (from $1.73 \pm 0.38$ at the start of therapy to $1.60 \pm 0.52$ at the end of therapy, $P=0.065$ ) (Table 2, Fig. 1A). In the multiple linear regression analysis, baseline BMI-SDS was the only factor that affected the change in body composition (delta-BMI-SDS; Table 3).

Suppression of the pituitary-gonadal axis by GnRHa administration led to a significant decrease in linear growth rates (height-SDS: from $1.32 \pm 0.81$ at baseline to $0.82 \pm 0.83$ at the end of therapy, $P<0.001$ ) (Table 2). This downward trend was consistent in both groups (height-SDS: normal-weight, from $1.21 \pm 0.70$ to $0.70 \pm 0.72, P<0.001$; overweight, from $1.47 \pm 0.94$ to $1.00 \pm 0.96, P<0.001)$.

\section{Intergroup difference in variation of BMI-SDS (delta-BMI-SDS) during GnRHa treatment}

The changes in BMI-SDS (delta-BMI-SDS) during the entire GnRHa treatment period were significantly different between the normal-weight and overweight groups $(0.15 \pm 0.44$ vs. $-0.14 \pm 0.40, P=0.005$ ) (Fig. 1B). The results were similar after adjustment for baseline covariates such as age, BA advancement,

Table 3. Multiple regression analysis of factors that influence changes in BMI-SDS ( $\triangle B M I-S D S)$ during gonadotropin-releasing hormone agonist treatment

\begin{tabular}{lccc}
\hline \multirow{2}{*}{ Covariate } & \multicolumn{3}{c}{$\Delta$ BMI SDS } \\
\cline { 2 - 4 } \multicolumn{1}{c}{ Bge } & $\beta$ & $P$-value \\
\hline Treatment duration & $-0.114 \pm 0.132$ & -0.133 & 0.392 \\
BA advancement & $-0.004 \pm 0.009$ & -0.074 & 0.653 \\
PAH & $-0.009 \pm 0.102$ & -0.011 & 0.930 \\
Baseline BMI-SDS & $-0.007 \pm 0.009$ & -0.091 & 0.417 \\
\hline B & $-0.220 \pm 0.055$ & -0.472 & $<0.001$ \\
\hline
\end{tabular}

BMI-SDS, body mass index-standard deviation score; SE, standard error; $\mathrm{BA}$, bone age; $\mathrm{PAH}$, predicted adult height.

Table 2. Changes in BMI-SDS and height-SDS in girls treated with gonadotropin-releasing hormone agonist at the start of therapy, 12 months later, and at the end of therapy

\begin{tabular}{|c|c|c|c|c|c|c|}
\hline \multirow{2}{*}{ Duration } & \multicolumn{2}{|c|}{ Total $(n=77)$} & \multicolumn{2}{|c|}{ Normal-weight $(n=46)$} & \multicolumn{2}{|c|}{ Overweight $(n=31)$} \\
\hline & BMI-SDS & Height-SDS & BMI-SDS & Height-SDS & BMI-SDS & Height-SDS \\
\hline Start of therapy & $0.83 \pm 0.95$ & $1.32 \pm 0.81$ & $0.24 \pm 0.73$ & $1.21 \pm 0.70$ & $1.73 \pm 0.38$ & $1.47 \pm 0.94$ \\
\hline 12 Months later & $0.91 \pm 0.86$ & $1.18 \pm 0.79$ & $0.36 \pm 0.63$ & $1.06 \pm 0.68$ & $1.73 \pm 0.41$ & $1.35 \pm 0.91$ \\
\hline End of therapy & $0.87 \pm 0.85$ & $0.82 \pm 0.83$ & $0.39 \pm 0.67$ & $0.70 \pm 0.72$ & $1.60 \pm 0.52$ & $1.00 \pm 0.96$ \\
\hline
\end{tabular}

Values are presented as mean \pm standard deviation. All SDS values are expressed relative to chronological age.

BMI, body mass index; SDS, standard deviation score. 

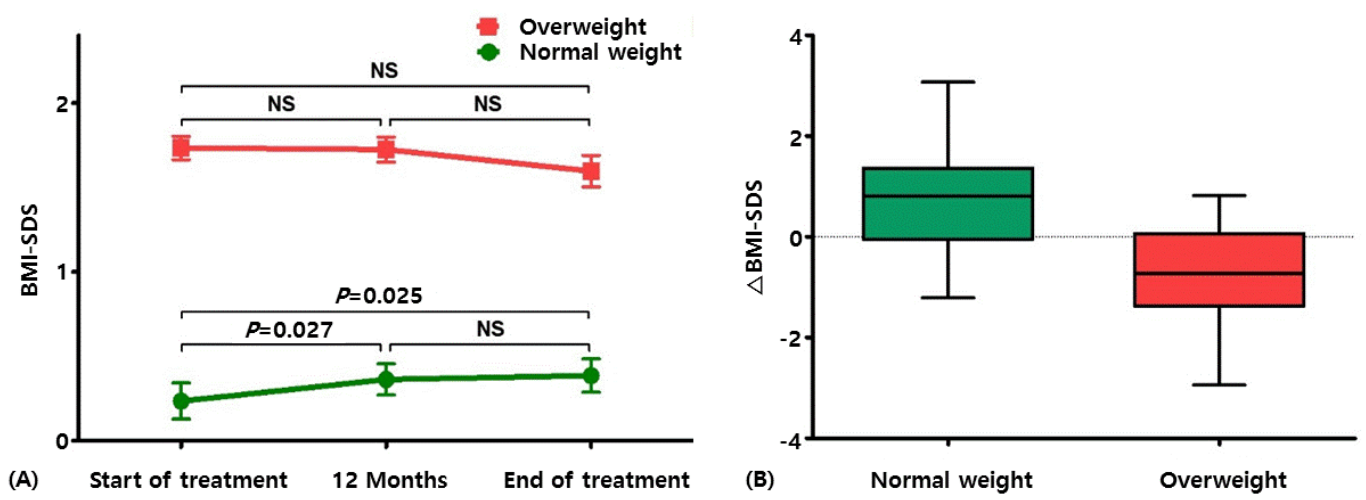

Fig. 1. (A) Serial changes in body mass index-standard deviation score (BMI-SDS) during gonadotropin-releasing hormone agonist treatment. (B) Comparison of variations in BMI-SDS ( $\triangle B M I-S D S)$ between the normal-weight and overweight groups. NS, not significant.

Table 4. Changes $(\Delta)$ in height and weight parameters during the gonadotropin-releasing hormone agonist treatment period

\begin{tabular}{lcrr}
\hline Variable & Normal-weight $(n=46)$ & Overweight $(n=31)$ & $P$-value \\
\hline$\Delta$ Height & $13.26 \pm 0.28$ & $14.37 \pm 0.35$ & 0.019 \\
$\Delta$ Weight & $11.42 \pm 0.53$ & $13.36 \pm 0.65$ & 0.028 \\
$\Delta$ BMI & $2.15 \pm 0.21$ & $2.04 \pm 0.25$ & 0.732 \\
$\Delta$ Height SDS & $-0.55 \pm 0.04$ & $-0.41 \pm 0.05$ & 0.033 \\
$\Delta$ Weight SDS & $0.78 \pm 0.81$ & $-0.01 \pm 0.99$ & 0.549 \\
$\Delta$ BMI SDS & $0.53 \pm 0.14$ & $-0.70 \pm 0.17$ & $<0.001$ \\
\hline
\end{tabular}

Values are presented as estimated mean \pm standard error after Bonferroni adjustment for multiple comparisons of the following baseline covariates: age, treatment duration, and bone age advancement.

BMI, body mass index; SDS, standard deviation score.

and treatment duration. We further analyzed height and weight parameters to elucidate the intergroup difference in delta-BMISDS. Gains in stature (delta-height) and weight (delta-weight) were both greater in the overweight group than in the normal control (Table 4). As for variations in height- and weight-SDS, statistical significance was observed only for delta-heightSDS $(P=0.033)$ (Table 4), indicating that the reduction in BMI was because statural growth outweighed weight gain in the overweight girls (Table 4).

\section{Discussion}

In the present study to address the effect of GnRHa treatment on body composition, we evaluated girls with CPP with different body compositions and demonstrated a significant difference in the patterns of the changes in BMI between the normal-weight and overweight CPP patients. Through stepwise regression analyses, we reaffirmed that weight status at the onset of treatment was the only factor that affected GnRHa-related changes in body composition. Unlike the overweight patients who maintained a relatively stable body composition, the girls with normal weight at baseline showed a significant increase in BMI-SDS during the treatment period, which was mainly attributable to the difference in statural growth between them.

Childhood obesity, an important predictor of morbidity and premature mortality in adulthood ${ }^{23)}$, was reported to be quite common in children with $\mathrm{CPP}^{8,9)}$. Likewise, the overall incidence of obesity and overweightness was alarmingly high in our study population. The prevalence of overt obesity (23\%) was also higher than that in the general pediatric population of Korea $(8 \% \text { for girls })^{24)}$. Considering its metabolic and cardiovascular complications such as impaired glucose tolerance, dyslipidemia, fatty-liver disease, hypertension, and systemic inflammation and its negative impact on psychosocial health, special cautions are required for these patients.

In the present study, the changes in BMI-SDS during GnRHa treatment showed a significant difference according to baseline BMI status. In fact, a similar finding was reported by some researchers, although the mechanism behind this phenomenon remains elusive ${ }^{14,15,21)}$. Wolters et al. ${ }^{21)}$ found that BMI-SDS increased during GnRHa treatment only in normal-weight children but not in overweight children. Two other studies that demonstrated an increase in BMI-SDS in both groups showed that the change in BMI-SDS was significantly greater in normalweight patients than in overweight patients ${ }^{14,15)}$. In line with the findings of previous studies, our findings strongly support that GnRHa treatment may have different effects on the body composition of CPP patients according to baseline BMI status. Based on our results, it appears reasonable to assume that this difference was attributable to the inhomogeneity in statural growth across the weight groups. Our findings, however, need more validation in a larger study population.

Growth during childhood and adolescence is controlled by many factors such as nutritional status, genes, physical activity, and hormones such as growth hormone/insulin-like growth factor 1 (GH/IGF-1) axis, thyroid, and gonadal steroids. CPP, a clinical condition characterized by an unusually early pubertal onset, initially can cause a tall stature, but rapid bone maturation that causes premature epiphyseal fusion leads to short adult stature. Therefore, the fundamental goal of GnRHa treatment is to delay puberty until a more appropriate age so that prepubertal 
growth can continue while slowing bone maturation ${ }^{25)}$. A number of studies have demonstrated that during the prepubertal phase, obese children exhibit higher growth velocity than lean subjects. However, this prepubertal advantage in growth is counterbalanced by an attenuated pubertal growth spurt and earlier pubertal maturation, achieving final heights similar to those in non-obese children ${ }^{26}$. This unique growth pattern of obese children provides an insight on why our overweight/ obese CPP patients, while still in prolonged prepubertal phase via GnRHa therapy, grew taller than the normal-weight patients did. More rapid bone maturation (delta BA: normal-weight vs. overweight, $1.31 \pm 0.06$ vs. $1.66 \pm 0.07 ; P<0.001$ ) in our overweight group also supports this hypothesis. In addition, GnRHa-driven GH/IGF-1 axis modulation and subsequent decrease in levels of biologically active IGF- ${ }^{27}$ might have played a role because somatic growth in obese children appeared to be largely GH independent ${ }^{26,27)}$. Further well-designed prospective studies are required to validate our findings and to investigate whether delaying puberty with GnRHa treatment results in more favorable long-term outcome particularly in CPP patients who are overweight or obese at baseline.

Controversy persists regarding the effect of GnRHa treatment on body fat and composition in CPP patients. Several studies have demonstrated that the percentage of fat mass or body fatSDS and BMI-SDS increased during GnRHa treatment ${ }^{14,15,28-30)}$. Conversely, some studies reported that GnRHa treatment had no effect on change in $\mathrm{BMI}^{13,16,18,31)}$. Another study found that BMI-SDS and obesity prevalence decreased during GnRHa therapy in girls with idiopathic $\mathrm{CPP}^{19)}$. Inconsistency in the literature may be affected by several factors such as lack of a control group, and differences in population age, treatment duration, and sex distribution. However, it should be noted that previous studies that demonstrated an increase in BMISDS during GnRHa treatment included mostly normal-weight children ${ }^{14,28,29)}$, while studies with negative results were based predominately on overweight children ${ }^{13,18,31)}$. Our findings that support the novel notion that GnRHa treatment-derived delayed puberty may lead to dissimilar linear growth according to individual body fat status would provide a plausible explanation for the observed inconsistencies.

Our study has some limitations. First, we had no control group because most of the CPP children underwent GnRHa treatment. Our population was relatively well-balanced (46 normal-weight patients vs. 31 overweight patients). As for a retrospective study, however, the present results could be confounded by a small, unequal sample size. Furthermore, although we performed analysis of covariance, one of the most commonly used statistical methods to adjust baseline covariates (e.g., age, BA advancement, and treatment duration), nonrandomized retrospective design of this study inevitably has a risk of introducing hidden bias ${ }^{32}$. The present findings could not be applied to the general CPP population because we only analyzed girls. On the other hand, however, unisexuality can be a forte considering the heterogeneities in growth pattern across sexes. Finally, although neither lifestyle modification nor strict dietary restriction was recommended during the treatment period, obese children, who are more likely to be self-conscious about fatness, may behave in different ways from normal-weight children, which might have biased our results.

The present study, which demonstrated a significant difference in the patterns of BMI changes between the normal- and overweight/obese CPP patients, strongly suggests that delaying puberty with GnRHa treatment has different effects on growth according to baseline body composition. Moreover, our systematic analyses based on auxological parameters provided a mechanistic insight into this phenomenon. Given the high incidence of obesity in CPP children, the present finding prompted further study to determine whether establishing an individualized treatment strategy based on pretreatment body composition has clinically relevant roles in promoting healthy growth and in preventing obesity in CPP patients.

\section{Conflict of interest}

No potential conflict of interest relevant to this article was reported.

\section{References}

1. Carel JC, Eugster EA, Rogol A, Ghizzoni L, Palmert MR; ESPE-LWPES GnRH Analogs Consensus Conference Group, et al. Consensus statement on the use of gonadotropin-releasing hormone analogs in children. Pediatrics 2009;123:e752-62.

2. Crowley WF Jr, Comite F, Vale W, Rivier J, Loriaux DL, Cutler GB Jr. Therapeutic use of pituitary desensitization with a long-acting lhrh agonist: a potential new treatment for idiopathic precocious puberty. J Clin Endocrinol Metab 1981;52:370-2.

3. Breyer P, Haider A, Pescovitz OH. Gonadotropin-releasing hormone agonists in the treatment of girls with central precocious puberty. Clin Obstet Gynecol 1993;36:764-72.

4. Carel JC, Lahlou N, Roger M, Chaussain JL. Precocious puberty and statural growth. Hum Reprod Update 2004;10:135-47.

5. Kauli R, Galatzer A, Kornreich L, Lazar L, Pertzelan A, Laron Z. Final height of girls with central precocious puberty, untreated versus treated with cyproterone acetate or $\mathrm{GnRH}$ analogue. A comparative study with re-evaluation of predictions by the Bayley-Pinneau method. Horm Res 1997;47:54-61.

6. Wang Y, Lobstein T. Worldwide trends in childhood overweight and obesity. Int J Pediatr Obes 2006;1:11-25.

7. Dunger DB, Ahmed ML, Ong KK. Effects of obesity on growth and puberty. Best Pract Res Clin Endocrinol Metab 2005; 19:375-90.

8. Chiumello G, Brambilla P, Guarneri MP, Russo G, Manzoni P, Sgaramella P. Precocious puberty and body composition: effects of GnRH analog treatment. J Pediatr Endocrinol 
Metab 2000;13 Suppl 1:791-4.

9. Currie C, Ahluwalia N, Godeau E, Nic Gabhainn S, Due $\mathrm{P}$, Currie DB. Is obesity at individual and national level associated with lower age at menarche? Evidence from 34 countries in the Health Behaviour in School-aged Children Study. J Adolesc Health 2012;50:621-6.

10. Pasquino AM, Pucarelli I, Accardo F, Demiraj V, Segni M, Di Nardo R. Long-term observation of 87 girls with idiopathic central precocious puberty treated with gonadotropinreleasing hormone analogs: impact on adult height, body mass index, bone mineral content, and reproductive function. J Clin Endocrinol Metab 2008;93:190-5.

11. Arrigo T, Cisternino M, Galluzzi F, Bertelloni S, Pasquino AM, Antoniazzi F, et al. Analysis of the factors affecting auxological response to GnRH agonist treatment and final height outcome in girls with idiopathic central precocious puberty. Eur J Endocrinol 1999;141:140-4.

12. Traggiai C, Perucchin PP, Zerbini K, Gastaldi R, De Biasio P, Lorini R. Outcome after depot gonadotrophinreleasing hormone agonist treatment for central precocious puberty: effects on body mass index and final height. Eur J Endocrinol 2005; 153:463-4.

13. Palmert MR, Mansfield MJ, Crowley WF Jr, Crigler JF Jr, Crawford JD, Boepple PA. Is obesity an outcome of gonadotropin-releasing hormone agonist administration? Analysis of growth and body composition in 110 patients with central precocious puberty. J Clin Endocrinol Metab 1999;84:4480-8.

14. Lee SJ, Yang EM, Seo JY, Kim CJ. Effects of gonadotropinreleasing hormone agonist therapy on body mass index and height in girls with central precocious puberty. Chonnam Med J 2012;48:27-31.

15. Aguiar AL, Couto-Silva AC, Vicente EJ, Freitas IC, Cruz T, Adan L. Weight evolution in girls treated for idiopathic central precocious puberty with GnRH analogues. J Pediatr Endocrinol Metab 2006;19:1327-34.

16. Shiasi Arani K, Heidari F. Gonadotropin-releasing hormone agonist therapy and obesity in girls. Int J Endocrinol Metab 2015;13:e23085.

17. Magiakou MA, Manousaki D, Papadaki M, Hadjidakis D, Levidou G, Vakaki M, et al. The efficacy and safety of gonadotropin-releasing hormone analog treatment in childhood and adolescence: a single center, long-term follow-up study. J Clin Endocrinol Metab 2010;95:109-17.

18. Głab E, Barg E, Wikiera B, Grabowski M, Noczyńska A. Influence of $\mathrm{GnRH}$ analog therapy on body mass in central precocious puberty. Pediatr Endocrinol Diabetes Metab 2009; 15:7-11.

19. Arrigo T, De Luca F, Antoniazzi F, Galluzzi F, Segni M, Rosano M, et al. Reduction of baseline body mass index under gonadotropin-suppressive therapy in girls with idiopathic precocious puberty. Eur J Endocrinol 2004;150:533-7.
20. van der Sluis IM, Boot AM, Krenning EP, Drop SL, de Muinck Keizer-Schrama SM. Longitudinal follow-up of bone density and body composition in children with precocious or early puberty before, during and after cessation of GnRH agonist therapy. J Clin Endocrinol Metab 2002;87:506-12.

21. Wolters B, Lass N, Reinehr T. Treatment with gonadotropinreleasing hormone analogues: different impact on body weight in normal-weight and overweight children. Horm Res Paediatr 2012;78:304-11.

22. Bayley N, Pinneau SR. Tables for predicting adult height from skeletal age: revised for use with the Greulich-Pyle hand standards. J Pediatr 1952;40:423-41.

23. Reilly JJ, Kelly J. Long-term impact of overweight and obesity in childhood and adolescence on morbidity and premature mortality in adulthood: systematic review. Int J Obes (Lond) 2011;35:891-8.

24. Oh K, Jang MJ, Lee NY, Moon JS, Lee CG, Yoo MH, et al. Prevalence and trends in obesity among Korean children and adolescents in 1997 and 2005. Korean J Pediatr 2008;51:950-5

25. Willemsen RH, Elleri D, Williams RM, Ong KK, Dunger DB. Pros and cons of GnRHa treatment for early puberty in girls. Nat Rev Endocrinol 2014;10:352-63.

26. De Leonibus C, Marcovecchio ML, Chiarelli F. Update on statural growth and pubertal development in obese children. Pediatr Rep 2012;4:e35.

27. Müller J, Juul A, Andersson AM, Sehested A, Skakkebaek NE. Hormonal changes during GnRH analogue therapy in children with central precocious puberty. J Pediatr Endocrinol Metab 2000;13 Suppl 1:739-46.

28. Oostdijk W, Rikken B, Schreuder S, Otten B, Odink R, Rouwé C, et al. Final height in central precocious puberty after long term treatment with a slow release GnRH agonist. Arch Dis Child 1996;75:292-7.

29. Antoniazzi F, Zamboni G, Bertoldo F, Lauriola S, Mengarda F, Pietrobelli A, et al. Bone mass at final height in precocious puberty after gonadotropin-releasing hormone agonist with and without calcium supplementation. J Clin Endocrinol Metab 2003;88:1096-101.

30. Ko JH, Lee HS, Lim JS, Kim SM, Hwang JS. Changes in bone mineral density and body composition in children with central precocious puberty and early puberty before and after one year of treatment with GnRH agonist. Horm Res Paediatr 2011;75:174-9.

31. Messaaoui A, Massa G, Tenoutasse S, Heinrichs C. Treatment of central precocious puberty with Gonadotropin-Releasing Hormone agonist (triptorelin) in girls: breast development, skeletal maturation, height and weight evolution during and after treatment. Rev Med Brux 2005;26:27-32.

32. Van Breukelen GJ. ANCOVA versus change from baseline: more power in randomized studies, more bias in nonrandomized studies [corrected]. J Clin Epidemiol 2006;59:920-5. 